\title{
UNIVERSITYOF
}

FORWARD

THINKING

WESTMINSTER用

WestminsterResearch

http://www.westminster.ac.uk/westminsterresearch

Other Bodies within Us: Shock, Affect and Reality Television

Audiences

Johanssen, J.

Reproduced with permission of Palgrave Macmillan.

This extract is taken from the author's original manuscript and has not been edited. The definitive, published, version of record is available here:

www.palgrave.com

The WestminsterResearch online digital archive at the University of Westminster aims to make the research output of the University available to a wider audience. Copyright and Moral Rights remain with the authors and/or copyright owners.

Whilst further distribution of specific materials from within this archive is forbidden, you may freely distribute the URL of WestminsterResearch: ((http://westminsterresearch.wmin.ac.uk/)).

In case of abuse or copyright appearing without permission e-mail repository@westminster.ac.uk 


\section{Other Bodies within Us: Shock, Affect and Reality Television Audiences}

Jacob Johanssen (Communication and Media Research Institute, University of Westminster, UK)

The chapter presents and analyses qualitative interview data from a research project on audiences of Embarrassing Bodies (Channel 4, UK, 2007-2015).

Embarrassing Bodies (EB) was a medical reality programme in which patients were diagnosed and treated by a team of doctors. It often featured graphic and detailed surgical sequences, as well as common, rare or tabooed medical conditions which were shown in front of the camera.

The project drew on Freudian psychoanalysis both as a research method for qualitative interviews (through the notion of free association), as well as in its analytical framework to analyse the affective relationships between subjects and their consumption of a television programme. I was interested in why viewers watched the programme and what their thoughts on the patients and doctors were (Johanssen forthcoming).

In this chapter, I pay particular attention to narratives from interviewees in which they spoke of or alluded to feeling offended, and in particular, disgusted and shocked by some of the $E B$ sequences. While the term 'offended' as such was seldom used, other words and expressions were uttered which, I suggest, circled around the feeling of being offended. These narratives often implicitly referred to affective responses to the television programme. Drawing on psychoanalysis, I argue that such feelings and specifically their articulation may in some instances function as a defensive act whereby that which offends the speaker is split off from them. In the case of $E B$ audiences the graphic display of so-called 'embarrassing' bodies made viewers who were part of the study think about and reflect on their own bodies and their own fragility.

Eventually, those aspects were often disavowed and dismissed during interviews by being labelled 'shocking' or 'extreme' and attributed to the patients only. For many interviewees, offence thus worked as a defence mechanism in order not to engage with functions or aspects of the body that we all share or may all potentially be confronted with one day. This was further shown in some interview narratives in which interviewees were keen to stress that their bodies were fundamentally different to the ones on the show.

I further argue that viewers also took pleasure in feeling shocked, offended and disgusted by what they saw. I conceptualise such modes of engagements as a perverse form of voyeurism. The interviewees in the sample were at once drawn to the abject bodies and rejected them through their narratives that spoke of offence, shock and affective responses. Many such narratives were coupled with moments of joy, excitement and entertainment. Rather than only figuring as a way of creating boundaries between audiences and content, such modes of engagement also legitimised the viewing of a programme that may otherwise be ethically problematic or 'trashy'. In speaking of their excitement, viewers embraced the offensive material they had split off at the same time. It enabled continued consumption for them in light 
of inter-subjective dynamics of an interview situation where they were asked questions about the programme. They could at once articulate being shocked and different from the 'embarrassing' bodies, while at the same time justifying their continued consumption to me by evoking light-hearted motives around entertainment.

\section{Offence, Disgust, Shock and Embarrassing Bodies}

Anne Graefer writes in her introduction to this volume that:

Generally media content is judged to be offensive when it contains offensive language, violence or depictions of sexual activity. Intrusive images of suffering or racist, classist or sexist depictions that contribute to stereotyping, or bias and inaccuracy in news reports and documentaries are also often reported as offending audiences. Graefer 2018, page

Offence and what constitutes as being offensive is difficult to define and often lies in the eye of the beholder. Reality TV as a genre has perhaps come to epitomise the category of offensive television with its reliance on stereotypes and graphic scenes of all kinds. In this chapter, I want to approach the 'affective messiness' (Graefer 2018, page) of offence as something that is clustered around other, equally slippery, signifiers and notions: disgust, shock, and the abject (Kristeva 1982). In the case of Embarrassing Bodies and in particular its scenes that depict operations, nudity or graphic medical conditions, many viewers I interviewed articulated a response that grappled with the content and made some references to feeling offended, shocked, or disgusted. The programme itself sets the tone in a particular way by often ridiculing and shaming the $E B$ participants. The $E B$ presenters / doctors themselves often perform shocked and offended reactions to the patients they see. For example:

Trina: Yeah, I had surgery done. I had part of my bowel removed, erm, from colitis.

Dr. Dawn: What where the symptoms that you were experiencing?

Trina: Erm, just, erm, being able to control, erm, toilet, having accidents, daily, erm.

Dr. Dawn: Oh my word! So you were actually leaking faeces, were you?

Trina: Basically.

Dr. Dawn: And was there a lot of blood and so on?

Trina: Yeah. (S5, E4: 09.45-10.26)

In response to a patient with tonsil stones, Dr. Dawn responds in another episode:

Now you've got big tonsils and you've got big pits, you've got big craters there, holes, dents, nooks and crannies in which all sorts of food particles are gonna get stuck. (S5, E3, 13.04-14.21) 
Such practices of performativity enable audience responses that articulate feelings of shock and offence that are totally justified on their part, because the presenters act similarly. Many interviewees spoke of their shock when viewing certain scenes:

Sometimes, I am, shocked probably isn't the right word, sometimes I am a little bit surprised that people's, almost lack of dignity to completely expose these things to the general public but, but it doesn't stop me watching it obviously (chuckles). I mean yeah, the one they did on the face of that chap whose face was completely decomposed from the tumour, I've seen a lot of horrible chopping things and I actually found that quite shocking, that's probably the only one that I've actually thought 'Oh, I don't know if I can actually look at that.' (I5, 162-168)

I think it was just quite shocking that people were either willing to come on TV and show everyone they had this thing that could be deemed embarrassing, erm, but also illnesses or disease that you didn't even know exist and some of the treatments for them, where you didn't realise that things were so invasive or shocking $(13,201-205)$

The two quotes above express both a feeling of shock and possibly offence by some of the bodies and body parts that are put on graphic display by the programme, but also the individual patients who go on the show are being labelled as lacking in dignity and shame. Their willingness to expose themselves to the cameras was met with shock by the two interviewees. 'Really? They're on the telly with that? Go to the chemist and get $\mathrm{x}$ or $\mathrm{y}$ but I suppose for them it's an opportunity to get on telly, the whole Andy Warhol fifteen minutes of fame, isn't it?' (15, 233-235), as one said.

In relation to initial feelings of shock, three interviewees spoke about the first time they had ever seen $E B$ :

Oh my god, erm it was a really long time ago now I think, I think I was quite shocked I think cos' there were some bits were it was like okay full on boobs and vaginas and penises on TV and like, I think back then maybe we weren't erm desensitised to it but I think we've become desensitised to seeing that kind of thing on TV now erm it's almost like as long as it's a medical problem and it is a penis then it's ok to show it on TV. It is just the way it seems but at the time I was a bit like 'Oh that's a bit gruesome showing that on TV' but then I don't know we have, I certainly have become desensitised to it, I don't know if other people have again it might be because l'm used to seeing that kind of horrible stuff now but l'm not as affected by it but I did think it was a bit shocking at first but then I also thought it was quite good that people who had these kind of problems could well could go somewhere but then I was a bit confused cos' I was thinking if you're so embarrassed again, why are you going on TV, yeah erm that was my initial reaction. $(17,213-226)$ 
I think, it was more, don't know, maybe a grotesque interest, a morbid interest in it, cos' to begin with, I think the first episode everything was quite extreme. It wasn't, it wasn't some of the things that you see now. Especially if you have the Embarrassing Bodies live clinic now, people show you what [inaudible] or whatever they've got erm I think it was just quite shocking that people were either willing to come on TV and show everyone they had this thing that could be deemed embarrassing erm but also illnesses or or disease that you didn't even know exist and some of the treatments for them, where you didn't realise that things were so invasive or shocking or, I think it definitely was a shock factor but in a good sense. $(12,195-206)$

Feelings of shock were presented here in relation to the beginning of the viewing of the programme. With more and more episodes consumed, the extreme and graphic nature of the programme subsided for the two viewers and they became somewhat used to or numb to the extraordinary scenes. Feelings of shock and disbelief about 'gruesome' and 'horrible' images later gave rise to 'morbid fascination' and a 'desensitised' way of viewing. Such initial responses thus eventually gave way to strong attachments and attractions to the show, as all interviewees emphasised to me that they watched it regularly whenever they could. Shock and offence may thus have functioned for Channel 4 as a calculated mechanism to lure audiences in so that they tuned in every week. But what were the viewers really shocked about? Was it naked or somehow 'other' bodies one normally does not see, unless one is a doctor? Was it the implicit shamelessness by the patients to expose their bodies to the viewers, as some interviewees remarked? Was it the graphic detail of operations and bodily conditions? As I go on to argue, those set of narratives presented above indicate a reaction on the surface and there are deeper motives and reasons for feelings of offence, shock and disgust. Before addressing those, it is useful to reflect on the social nature of the strong reactions to the show that were voiced by the interviewees. Such reactions are specifically and socially coded. What is offensive may vary according to different societies and belief systems. Nothing is offensive in its own right. We learn to be offended by various situations. In the first instance, viewers may have felt an (unconscious) need to respond to a call to be offended and to stress such sentiments during the interviews. They were being questioned by a university researcher on their motives for watching the programme and rather than talk about commonly articulated motives for watching reality television - escapism, Schadenfreude, entertainment (Hall 2006; Sender 2012; Skeggs and Wood 2012) notions of shock, or disbelief were stressed early on in each interview. This may have occurred because the articulated narratives were very much some that one would expect given EB's status as a unique media text that broke with conventions even for Channel 4 standards at the time. Motives such as escapism or entertainment may have been perceived as misplaced by the viewers if articulated to me. The illusive state of being shocked was thus first evoked in order to conform to social expectations. Expectations, interviewees believed I held. In reality, I had not told them what I thought of the show. According to widely held beliefs and as articulated by the programme itself, the scenes on display simply must be shocking, 
embarrassing, extreme - even offensive to some. This may seem like common sense. Why is this the case? As the interviews went on and narratives flowed, the specific notion of disgust was mobilised by some in more detail and the viewers' positions were more specifically articulated:

I don't watch One Born Every Minute because I don't particularly like it, I don't wanna watch it, it's not very, I find that disgusting, so I think it all depends, some people like to watch operations and disgusting conditions, essentially they are not nice, it's not something you'd want to look at if you want to relax but then some of us I reckon are just interested and we're not all gonna be doctors, we don't all want to see I don't know cysts and things like that, it's just yeah. (I6, 159-166)

I was shocked last week with the chap, the chap who had his eye removed that was that was ama-, I guess almost I wanted to look away, part of me does that and part of me always wants to look so that I think that's probably the most shocked l've ever been to be honest and the fact that he's still sort of talking so normally, l've never seen anything you know as quite extreme, so that was that was really interesting, so yeah I mean obviously some of the other things, I suppose the sort of erm, erm you know there's the usual kind of gross out things I guess and and stuff to do with sexual things I suppose. I suppose they have to put a full range of the things, again it ultimately has to entertain, hasn't it? But I suppose really, I'm just really interested in things that can happen to all our bodies so, you know, it can range from 'Oh my god' to, back to just 'Oh that's quite interesting'. (17, 118-127)

Yeah, yeah, yeah definitely there's something like, you know when there's like really gross infections when you kind of things that is quite disgusting, like when things are like septic or whatever or just general like people go on there with all manner of things don't they? Erm and like erm you never really know what you're gonna get but there's a few times l've kind of gone 'Eurgh', it makes me feel really squeamish but I think cos' they also kind of do like a lot of, they'll show like operations and stuff, they're not afraid to show the really gory stuff. I think that helps. I think it helps, it wouldn't be right if that show kind of didn't show you stuff, you know it's important that it does. (I10, 207-215)

Writing on the affective power of disgust, Sara Ahmed (2004) argues: 'Disgust pulls us away from the object, a pulling that feels almost involuntary, as if our bodies were thinking for us, on behalf of us.' (Ahmed 2004, 85). This image of the body that suddenly pulls away was also present in a lot of the interview narratives as they spoke of moments of turning away from the television screen when they were too shocked and disgusted to look. We could interpret feelings of disgust as mere biological responses that we have been trained to execute: a close-up of a gaping wound is disgusting and our gut feeling affirms this, we may feel our stomach churn or sensations of nausea. However, there is a political dimension to disgust and shock. Disgust reinforces and secures a border between the one who is (made to be) 
disgusting and the one who is disgusted (Ahmed 2004, 87), the patient who was leaking faeces and the clean, proper doctor who has reinforced the border between them by asking the question. Such forms of separation are relayed to audiences. Perceiving something as disgusting entails morality, as Winfried Menninghaus (2003) writes: the body before us 'should not be, at least not for us and in our presence. It should go away.' (Menninghaus 2003, 53, italics in original). What is interesting about the above narratives is that bodies are made to be disgusting through speech acts. They are disgusting, or gross, according to the viewers. Bodies, conditions and things are of a negative quality. They are made to acquire and become digust/ing as an overpowering quality that overshadows everything else about them. Some scenes in Embarrassing Bodies (and related programmes) were thus termed 'disgusting' by viewers, but what lies behind the act of casting something or someone as disgusting?

Julia Kristeva (1982) has coined the notion of 'the abject', an affective response to someone or something which is similar to disgust. She argued that the abject puts me 'at the border of my condition as a living being.' (Kristeva 1982, 4). I am affected by an experience that is unfamiliar and react in defence and fascination. I look and look away at the same time.

I suggest that such speech acts by viewers were manifestations of an unconscious desire to create a border between patients and themselves, to draw a line between the 'embarrassing' and not-embarrassing bodies. The great detail and passion used by the interviewees to talk about their shock, offence and disgust thus serves a defensive purpose. They split themselves off from the patients and from fears of becoming embarrassing bodies themselves. This will be illuminated more in the next section.

\section{Feeling Offended as a Defensive Act}

Many viewers were keen to stress how different they were from the patients. I suggest that feelings of offence, shock and disgust were particularly emphasised to me during the interviews so that the interviewees could differentiate themselves from the patients on $E B$. Many of the conditions presented on the programme are conditions that each and every one of us could have, be it as a result of an accident, ageing, a botched surgery, etc. 'There's no shame, we're all the same', as the show's slogan states. In that sense, there is nothing extraordinary about the programme. This sensation may have occurred during the interviews and offended the individuals' narcissistic fantasies of their own ideal and perfect bodies. Kristeva argues that seeing the abject results in 'a narcissistic crisis' $(1982,14)$ for the ego, because we are reminded that we are in fact not perfect or forever young. In moments of abjection, we are reminded of our finitude and bodily limits. Some of the scenes of $E B$ touch something that is always already lost in the ego (according to psychoanalysis): a coherent sense of a whole and unified subjectivity. Thus, scenes of such nature are offending to the ideal fantasy of the ego as one of coherence and invulnerability and must be (unconsciously) split off. Viewers spoke about some of their responses to and thoughts of the programme in specifically affective terms that showed a difficulty of speaking about them: "Eeeurgh" you are imagining the pain but 
that's what it is, you are imagining the pain, you don't know what it is like.' (19, 409410), as one remarked. A woman said:

Just the surprise, I mean I have never seen something so magnified. I mean we all have an idea of how, especially women, we have an idea of how it is but this kind of, it was so magnified, erm, I might say, probably for a few seconds I might felt a bit like 'eurgh' [...]. (I1, 647-650)

I mean yeah you do get those sort of 'eeeh' squirmy moments where you know you can't even look at the screen. (I2), 367-368)

Attempts to describe affective responses such as 'eurgh' or 'eeeh' point to difficulties on part of the viewers to speak about their embodied reactions to the programme. The narcissistic crisis that comes about as a result of viewing certain scenes is met with such strong reactions that viewers have difficulty to render them into discourse. The body speaks itself in such responses (Johanssen 2016).

By rendering scenes as shocking or disgusting, viewers made use of strong terminology in order to dis-identify with them. They imagined what it may be like to have the bodies that are put on display in front of the cameras and this created a fear of becoming like them. There is almost an affective contagion through the television screen that needs to be combated: 'Yeah if it's all too real then I do, don't know, it could be me, it can still be me, I can catch anything and be affected' (16, 203-204), as one person said. A man said that he could not look at other men having surgery:

I didn't wanna look because especially if it was a guy and he had a because I couldn't look, oh if I had that erm that they went into surgery and if they were doing something and I can't watch that you know. 19, 215-217

A female interviewee gave a very detailed account of a body she did not want ending up having:

You know thinking what life must be like to be, to have that impact on your body and how sometimes that's a choice as well! How can you choose to allow yourself to become quite so big? Some people don't mind if they're a certain size but when you get so big that you can't even wipe your own bum after going to the loo that's something else! I don't think we really learn much from those problems but its perhaps more of a shock factor, to people or if you're thinking that you're getting a bit big and you wanna lose a bit of weight that might inspire you, thinking 'You know what, I don't wanna end up like that, so l've got a choice to do something about it.'. I2, 390-400

We can see how disgust, shock, offence and affective responses serve as defence mechanisms for the viewers that stress the difference between the viewer's bodies and the patient's bodies. Many viewers were keen to point out to me how healthy 
they were and that they were thankful for their bodies. I asked them, if they would consider going on the programme, but all declined:

\section{I: And would you yourself go on Embarrassing Bodies?}

110: No. Erm erm, no, I, I mean I'm thankful that l've never had to see anyone about anything embarrassing erm which is I'm really thankful for but you know I don't think I'd go on it unless no, no I can't I can't see a reason why. (I10, 265268)

The almost performative utterances of disgust, shock and offence during the interviews thus serve a defensive purpose of splitting off (Klein 1988) fantasies of mortality, changing bodies or sudden medical conditions that result in bodies that are out of control. It may have also been uttered in relation to the interview dynamics and that interviewees did not wish to appear to be 'weak' or 'embarrassing' if they had told me that they have fears of becoming like the bodies on the programme who are in need of, sometimes urgent, medical help. Instead, interviewees emphasised how different their bodies were. For instance, one interviewee said:

Yeah, fine I am pretty happy and healthy you know and haven't really got any hang ups, erm, yeah [inaudible]. I think shows like this do make you appreciate, you know everyone is like critical of themselves but shows like this they put a perspective in people, people go through a lot worse, like scary stuff [...]. (I10, 323-326)

A young woman I spoke to remarked:

Erm, I'm very lucky, I don't, I think stretch marks are the one, like when people come on and they say 'I have really bad stretch marks' and you get to see their body and I feel better because I know I'm not the only one, erm, I, I also don't like the weight I am, l'd like to lose weight so when chubby people come on like 'Yeah, you go,' I feel better but, erm, I tend to be, I'm quite lucky to be honest, I think compared to people who go on it. It makes me feel normal like the small mistakes I have, it's not the end of the world. $(16,250-255)$

One female said:

Erm on the whole, I'd say fairly okay, I mean, I suppose I have like some irrational problems like l've got a bit of a belly on me, like the other day someone actually thought I was pregnant on the tube which I was quite shocked about [...]. (I8, 437439)

Those narratives further distanced the interviewees from the patients. Their bodies are healthy, happy, lucky, okay. Not embarrassing. Indeed, one woman was shocked when being mistakenly perceived as pregnant. One may understand how $E B$ as a media text may have served an (unconscious) function of defending against fears of 
becoming out of shape, or out of control. Those fears were not really spoken about in the interviews but expressed themselves in the passionate rejection of the patient bodies and in the emphasis of the healthy bodies of the interviewees. I do not mean to discredit such feelings. We all have them. It is however problematic to render certain bodies shocking, disgusting or offensive and not others. As I discussed, such words were used by the interviewees for two reasons: two conform to social expectations in an interview situation, and to (unconsciously) defend against fears of becoming a body in need of medical help.

The reader may ask a question at this point: if viewers were so shocked, offended and (unconsciously) fearful of the programme - why did they continue to consume it week after week? Psychoanalysis can help in answering this question: ultimately, there was a degree of perverse pleasure in the consumption of the show by viewers.

\section{A Perverse Form of Voyeurism: Embracing and Rejecting Embarrassing Bodies}

In addition to narratives of shock, offence or disgust, many viewers also spoke of feelings of excitement and of how entertaining the programme was to them. Such narratives were arguably less socially acceptable given the 'trashy' and shocking nature of most reality television formats, but they were uttered nonetheless.

I: And when you watch a recorded episode cos' then you can sort of rewind, do you sometimes do that?

12: Yeah, if they have said something particularly shocking or if I have missed it erm or my boyfriend said 'Oh my god, did you catch that bit?' (I2, 311-314)

I like, I really like parasites so parasitology, so if they do, I think at some point, James or whatever his name is, had to swallow tape worms and they went off and saw how they lived in his gut essentially, I thought that was really cool. I quite like Malaria or something like when they pick up on pretty exciting things rather than just boring, like I don't mean to be harsh but like dermatitis and acne yeah it is, when it's really bad, it's really bad but it's quite common so I prefer to see a bit [inaudible] especially from people who travel and catch things there. I don't particular like, I like it when like people have something wrong with their genitalia, I think it's quite interesting but erm like STIs are a bit boring now cos' you heard it everywhere, when they go on the beach and they talk to people like what they do over the weekend when they're drunk, you're just like 'Yeah, we all know this.'. (I6, 175-184)

I'm always excited to watch it, cos' I wanna see what's on next (laughs)! Erm, I just find it really interesting. (I3, 222-223)

Excited. Erm, yeah quite that's why I like to record it cos' I hate the adverts, I need to be on it! Like, I kinda like stop because I want to see what happens next and I don't like when they talk too much, I'm just like 'no, no, show me, show me everything.' Erm, yeah, excited is the word, it's quite sad. (16, 77-80) 
In speaking of their excitement about the show, more light-hearted motives came to the fore that may be associated with entertaining qualities. Viewers were able to embrace and reject Embarrassing Bodies at the same time. They had rejected and othered the patient's bodies, but in speaking of their excitement, they were able to embrace them again. This suggests that experiencing the affective states of disgust, shock and offence was oddly pleasurable for the viewers. I call such forms of engagement a perverse form of voyeurism. '[C]ausing offence is always tinged with a certain jouissance, and being offensive in public is a political act brimming with psychic investments.' (Baraitser 2008, 424). Perhaps the same is true to a degree for being or feeling offended. While such feelings may be perceived as deeply unpleasant and negative, a psychoanalytic angle suggests that they can be oddly pleasant and satisfying at the same time. I suggest that this was the case of the interviews. Two psychoanalytic concepts allow us to think about this further: perversion and voyeurism. As a concept which originates from psychoanalysis, voyeurism primarily refers to a sexual gratification from looking at other people without being seen (Fenichel 1995). For Freud (1981), voyeurism has a distinctly sexual component. He described it as an act of looking without being seen by the other so that sexual pleasure can be achieved. Fenichel (1995) argued that in looking at a scene (of sexual intercourse for instance), voyeurs are (unconsciously) reminded of childhood experiences, such as seeing a parent's genitals. These experiences aroused an anxiety in them. Such scenes that resemble the initial experiences of voyeurs are repeated again and again in order to achieve mastery over them. However, there can also be a voyeuristic dimension to viewing practices which are not aimed at sexual arousal or pleasure (Metzl 2004).

Embarrassing Bodies viewers perhaps exhibited such voyeuristic viewing practices because audiences are able to see bodies they would normally never see, unless they were working in the medical sector. The programme may thus have a highly voyeuristic appeal. Rather than speaking about such a voyeuristic appeal, the viewers in the study turned it around by stressing their feelings of offence, shock and disgust.

I argue that the viewing practices and the narratives about them discussed in this chapter also go beyond mere voyeurism. They are explicitly coupled with perverse tendencies. Post-Freudian psychoanalysts have defined perversion as a particular psychodynamic relationship. The pervert's object (be it a real person, or a thing) is (ab)used and handled instrumentally while at the same time being valued and adored. The pervert attempts to enact mastery over another and through this act ultimately disavows human fragility, loss and death (Lacan 1994; McDougal 1995; Ogden 1996). While the relationship between the viewers and the programme was of course not exactly the same as a perverse relationship between two human beings, some tendencies that characterise the psychodynamics of perversion were apparent nonetheless.

In speaking of their excitement, viewers were able to (unconsciously) reverse the defensive reactions to the patients. They were able to enjoy their own disgust, shock and offence. After all, they had reminded themselves and myself during the interviews of how different they were. Their fears of becoming like the patients were 
thus completely unreasonable. The patients' suffering and 'otherness' thus enabled a form of agency in the viewers' minds that allowed them to manipulate the patients as objects to be excited about. The patient's bodies could be mentally used for the purposes of being offending and entertaining. Viewers could rewind and re-live their shock and shudder in excitement at naked bodies. They could be excited about and entertained by their own disgust and take perverse pleasure in it as well as in the patients' miseries.

I think it's very, it is entertaining, I like the sort of production style of it, you know it flows very well and, erm, it feels wrong, I must admit, it feels wrong sometimes watching it for entertainment but you know what I mean, it's, erm, I find it very interesting, although l've always been interested in medical stuff like that so. (I2, 357-360)

Another interviewee said: 'I suppose anyone who watches it has got a general, in a weird way to be entertained by some of the grossness that can happen to the body' (17, 76-78). A female remarked: 'I do also think that people watch it for entertainment value and, and I think that I'm probably being guilty of that as well to be honest.' (I8, 472-476). Through enjoying and being entertained by the programme, viewers were able to disavow their own (unconscious) fears of the fragile human existence. Their initial narratives of shock, offence and disgust acquire another quality when put in relation to their emphasis on how different their bodies were from the patients' and how excited they were about the show. Their narratives thus not only functioned as a way to articulate socially expected responses to the 'extreme' scenes of the programme, but also enabled them to acquire a sense of agency and mastery over their unconscious fears and defence mechanisms. It is this agency that bears perverse tendencies because it disavows the viewers' possible anxieties about their own bodies as well as the patient's real medical problems. The patients undoubtedly appeared on the programme not because they wanted to act as offensiveentertaining bodies, but because they sought genuine medical help.

The interview narratives also served as an additional justification to the interviewees and to myself as to why they kept watching the programme. Rather than stopping to consume it because they were too shocked or offended, the emphasis on their bodily difference and the entertaining qualities of the series enabled a continued consumption. The paradox of embracing and rejecting the bodies on the programme was thus kept in a dynamic motion through stressing the light-hearted motives.

\section{Conclusion: Loving the Shock}

What might be the implications of the model of pleasurable shock, disgust and offence, which I have put forward in this chapter, be for wider cultural analyses of our times?

As numerous contributors to this volume have identified in their chapters, we live in an age where 'the right to offend' is diagnosed as being under threat by various commentators. So-called 'political correctness' has made it more difficult to offend as certain discourses are no longer tolerated in public, university and media spaces. Of 
course, those who have bemoaned such fading of free speech are the ones who often were the perpetrators of such discourses: sexist, racist, classist, ableist narratives which are no longer tolerated. Offence, shock and disgust are something societies should tolerate in order to guarantee freedom of expression, some voices say. Being offended that the right to offend is under treat is perhaps an irony that we have to learn to come to terms with. I would suggest that the spectacles of reality television and social media have enabled an acceleration of offence, disgust and shock where the next scandal is just around the corner, it only takes one tweet for another 'shit storm' to erupt. Reality television production houses and social media companies of course love offence, disgust and shock, for they attract more audiences, clicks and generate profit through data mining for the latter. Audiences have perhaps equally bought into the viral nature of those affective states. Yet another, outrageous tweet by Donald Trump for example allows us all to be united in collective offence and uproar. But doesn't it secretly give us a feeling of joy, euphoria and collectivity? As affective states, offence, disgust and shock enable collective movements and allow us to be moved collectively. While one must be careful not to generalise in light of the various justified waves of offence that we have witnessed in the last few years in relation to sexualised, racialized and ableist violence, there is perhaps a perverse tendency in the reactions to some of them that are marked by a sense of collective pleasure.

In the light of the newly formed coalition government between Austria's conservative ÖVP and Jörg Haider's right-wing FPÖ in 2000, Slavoj Žižek (2000) wondered 'why we all love to hate Haider' (2000, 37). Haider had become a common denominator that all so-called democratic political parties and citizens could project their hatred on.

Plain to see, in fact, is the structural role of the populist Right in the legitimation of current liberal-democratic hegemony. For what this Right-Buchanan, Le Pen, Haider-supplies is the negative common denominator of the entire established political spectrum. These are the excluded ones who, by this very exclusion (their 'unacceptability' for governmental office), furnish the proof of the benevolence of the official system. (Žižek 2000, 37)

While Žižek has done enough to offend people through his provocative and often problematic statements (see e.g. Ahmed 2008 for a critical discussion), he has perhaps made a point here. Are we dependent on the Embarrassing Bodies patients, Trump, Weinstein and other contemporary abject phenomena in order to reassure ourselves of our good qualities as citizens? To an extent, both subjects like Trump and the medicalised bodies on EB represent bodies that are (made to be) out of control. They need to be inhibited, disciplined and policed by our discourses so that a functioning symbolic order is upheld and that we can reassure ourselves of how 'good' we are. Our shock at them is thus not only a 'natural' response in light of what is deemed good and moral, but leads to a collective force that produces endless commentaries that express an almost pleasurable shock that is coupled with (justified) offence. 


\section{References}

Ahmed, Sara. "Liberal Multiculturalism is the Hegemony-It's an Empirical Fact: A Response to Slavoj Žižek," Darkmatter: Post-colonial Futures, (2008).

http://www.darkmatter101.org/site/2008/02/19/\%E2\%80\%98liberal-multiculturalismis-the-hegemony-\%E2\%80\%93-its-an-empirical-fact\%E2\%80\%99-a-response-toslavoj-zizek/.

Ahmed, Sara. The Cultural Politics of Emotion. Edinburgh: Edinburgh University Press, 2004.

Baraitser, Lisa. "On Giving and Taking Offence," Psychoanalysis, Culture \& Society 13, no. 4 (2008): 423-427.

Fenichel, Otto. The Psychoanalytic Theory of Neurosis. London: Routledge, 1995.

Freud, Sigmund. "Repression". In: The Standard Edition of the Complete Psychological Works of Sigmund Freud. Volume XIV. On the History of the Psycho-analytic movement, papers on Metapsychology and other works. London: The Hogarth Press and the Institute of Psycho-Analysis, 1981.

Graefer, Anne. "Introduction," in Media and the Politics of Offence, ed. Anne Graefer (Basingstoke: Palgrave Macmillan, 2018), pp-pp.

Hall, Alice. "Viewers' Perceptions of Reality Programs," Communication Quarterly, 54, no. 2 (2006): 191-211.

Johanssen, Jacob. "Not Belonging to One's Self: Affect on Facebook's Site Governance Page," International Journal of Cultural Studies. 2016, 21, 2, pp. 207222, http://journals.sagepub.com/doi/full/10.1177/1367877916666116

Johanssen, Jacob. Psychoanalysis and Digital Culture: Audiences, Social Media, and Big Data. London: Routledge, forthcoming.

Klein, Melanie. Love, Guilt and Reparation and Other Works. 1921-1945. London: Virago, 1988.

Kristeva, Julia. Powers of Horror. An Essay on Abjection. New York: Columbia University Press, 1982.

Lacan, Jacques. Le Seminaire. Livre IV: La Relation D'Objet. Paris: du Seuil, 1994.

McDougall, Joyce. The Many Faces of Eros. New York: Norton, 1995.

Menninghaus, Winfried. Disgust: Theory and History of a Strong Sensation. New York: SUNY Press, 2003. 
Metzl, Jonathan. "From Scopophilia to Survivor. A brief History of Voyeurism," Textual Practice, 18, no. 3 (2004): 415-434.

Ogden, Thomas. "The Perverse Subject of Analysis," Journal of the American Psychoanalytic Association, 44 (1996): 1121-1146.

Sender, Katherine. The Makeover. Reality Television and Reflexive Audiences. New York: New York University Press, 2012.

Skeggs, Beverly and Helen Wood. Reacting to Reality Television. Performance, Audience and Value. London: Routledge, 2012.

Žižek, Slavoj. Why we all Love to Hate Haider." New Left Review, Volume 2 (2000): 37-45. 